\title{
Fulminant type 1 diabetes mellitus
}

\author{
Ryota Inokuchi, ${ }^{1,2}$ Akinori Matsumoto, ${ }^{1}$ Hajime Odajima, ${ }^{3}$ Kazuaki Shinohara ${ }^{1}$
}

${ }^{1}$ Department of Emergency and Critical Care Medicine, Ohta Nishinouchi Hospital, Koriyama, Fukushima, Japan

${ }^{2}$ Department of Emergency and Critical Care Medicine, The University of Tokyo Hospital, Bunkyo-ku, Tokyo, Japan

${ }^{3}$ Department of Pathology, Ohta Nishinouchi Hospital, Koriyama, Fukushima, Japan

Correspondence to Dr Ryota Inokuchi, inokuchir-icu@h.u-tokyo.ac.jp

\section{Summary}

We present a fatal case of fulminant type 1 diabetes mellitus that was initially diagnosed as upper respiratory tract infection based on pharyngeal redness at a clinic. However, the patient then went into cardiopulmonary arrest, and was transferred to our hospital for treatment. Testing revealed very high levels of blood glucose $(86.9 \mathrm{mmol} / \mathrm{l})$, urinary glucose $(2+)$ and ketones $(4+)$. His glycosylated haemoglobin level was almost normal $(6.2 \%$; normal $<6.2 \%)$. Autopsy revealed marked depletion and atrophy of the islets of Langerhans.

\section{BACKGROUND}

Fulminant type 1 diabetes mellitus (FT1DM) is a rare condition, with extremely rapid progression to critical illness. Patients most frequently present with symptoms similar to the common cold, and are usually young or middle-aged. Failure by physicians to consider this condition may result in patient death.

\section{CASE PRESENTATION}

A 29-year-old Japanese man with cardiopulmonary arrest was transferred to the emergency room of our hospital. He had been physically well until 3 days previously, when he had complained of fever and abdominal pain. His family history was unremarkable. On the day of admission to our hospital, he had initially presented to a different clinic with loss of appetite. He was observed to have pharyngeal redness, and was diagnosed with an upper respiratory tract infection. After receiving intravenous fluids and antibiotics (erythromycin), he felt well and went home. However, later that day, he became unwell again and returned to the clinic, where he collapsed $1 \underline{\mathrm{h}}$ after admission. As he did not have a palpable pulse, cardiopulmonary resuscitation was initiated immediately, including tracheal intubation and intravenous epinephrine administration. As the clinic was unable to manage the patient due to a lack of equipment and manpower, he was transferred to our hospital. During the transfer, spontaneous circulation was restored, $10 \mathrm{~min}$ after his collapse. His initial electrocardiographic monitoring results are unknown.

On arrival in our emergency department, his body temperature was $35.4{ }^{\circ} \mathrm{C}$, and he had a pulse rate of 119 beats/min, blood pressure of $140 / 61 \mathrm{~mm} \mathrm{Hg}$ and Glasgow Coma Scale score of E1V1M1. We did not detect rash, anisocoria, heart murmur, chest rales, tongue biting or seizure activity.

\section{INVESTIGATIONS}

Following the return of spontaneous circulation, the biochemical parameters of the patient were examined.
Laboratory testing revealed a very high blood glucose level of $86.9 \mathrm{mmol} / \mathrm{l}$, serum $\mathrm{Na} 119 \mathrm{mEq} / \mathrm{l}$ and serum $\mathrm{K}$ $6.3 \mathrm{mEq} / \mathrm{l}$, and arterial blood gas revealed $\mathrm{pH} 6.929, \mathrm{PO}_{2}$ 69.3 Torr, $\mathrm{PCO}_{2} 65.2 \mathrm{~mm} \mathrm{Hg}, \mathrm{HCO}_{3} 13.3 \mathrm{mmol} / \mathrm{l}$ and base excess $-19.9 \mathrm{mmol} / \mathrm{l}$ under $\mathrm{FiO}_{2}=1.0$. Urine testing indicated glucose $(2+)$ and ketones $(4+)$. However, his HbA1c level was almost normal (6.2\%; normal <6.2\%). His serum amylase level, other electrolyte levels $(\mathrm{Mg}$, inorganic phosphorous and $\mathrm{Ca}$ ), urine drug levels, echocardiographic findings and the results of coagulation function tests and thyroid function tests were normal. ECG showed peaked $\mathrm{T}$ waves, but no loss of $\mathrm{P}$ waves. Chest X-ray revealed pulmonary oedema. Head CT did not detect intracranial haemorrhage, and contrast-enhanced CT did not detect a dissection, pneumothorax or pulmonary embolism.

Anti-GAD antibody was not detected. Subsequent testing was positive for human leucocyte antigens (HLA)-DR4, -DR13, -DQ1 and -DO4. Fasting serum $\mathrm{C}$-peptide level and urinary C-peptide excretion were not measured.

\section{DIFFERENTIAL DIAGNOSIS}

- Hyperglycaemia (due to FT1DM)

- Coronary artery spasm

- Congenital coronary artery abnormality (such as Kawasaki disease)

- Myocarditis

- Arteritis

- Idiopathic ventricular fibrillation

- Brugada syndrome (transient ECG abnormalities)

- Long QT syndrome (due to erythromycin)

- Familial sudden cardiac death

- Coronary dissection

- Poisoning (undetectable for urine drug tests).

\section{TREATMENT}

On admission, although his initial electrocardiographic monitoring results at the clinic were unknown, witness and bystander cardiopulmonary resuscitation was performed; 
therefore, hypothermia therapy was initiated. In addition, isotonic saline infusion and intensive insulin therapy using short-acting insulin was initiated for FT1DM. Hyperkalaemia due to severe acidosis immediately decreased following the isotonic saline infusion, and ECG findings were normal.

\section{OUTCOME AND FOLLOW-UP}

The patient's fasting plasma glucose level gradually decreased, at approximately $2.7-5.5 \mathrm{mmol} / \mathrm{dl}$ per hour. On the second day of admission, anisocoria was observed, and a CT scan revealed severe brain oedema. His condition worsened, and he died on day 4. Arrhythmia was not detected during hospitalisation.

According to the autopsy results, immunohistochemical examination of the pancreas using antiglucagon, antiinsulin and antichromogranin $\mathrm{A}$ antibodies revealed a paucity of islets of Langerhans; in most of the remaining islets, there were no insulin-positive cells (figure 1A), and few glucagon-positive cells were observed (figure $1 \mathrm{~B}$ ). In addition, CD8-positive $\mathrm{T}$ cells, which reportedly contribute to selective pancreatic $\beta$-cell destruction, were observed in the pancreas (figure 1C). Other internal organs, including the heart and great vessels, exhibited no abnormalities.

\section{DISCUSSION}

FT1DM is defined as a subtype of diabetes mellitus that is characterised by extremely rapid progression of hyperglycaemia and ketoacidosis due to the destruction of pancreatic $\beta$ cells. A diagnosis of FT1DM can be made by the evaluation of the following biochemical parameters: (1) high urinary and/or serum ketone body concentration; (2) high plasma glucose level (>16.0 mmol/1, $288 \mathrm{mg} / \mathrm{dl}$ ) and glycosylated haemoglobin (HbA1c) level (<69 mmol/ mol, 8.5\%); and (3) low urinary C-peptide excretion or serum C-peptide level. ${ }^{1}$

FT1DM - an important subtype of diabetes-is observed particularly in East Asia, although Caucasian cases have also been reported. ${ }^{2}$ The mean $( \pm S D)$ age at presentation has been reported to be significantly higher in men $(42.8 \pm 14.8$ years) than in women $(35.1 \pm 15.8$ years $)(p=0.002) .{ }^{3}$ Failure to diagnose FT1DM may result in deaths in young or middle-aged patients.

Patients with FT1DM experience extremely rapid progression to critical illness. However, the most common symptoms are similar to those of the common cold, such as thirst (93.7\%); abdominal symptoms such as nausea, vomiting and abdominal pain (72.5\%); flu-like symptoms
$(71.7 \%)$; and drowsiness $(45.2 \%){ }^{3}$ In a region where common cold is prevalent, FT1DM may therefore not be clinically diagnosed. To our knowledge, no published case reports have described the respiration rate of patients with FT1DM, but a patient with diabetic ketoacidosis (DKA) may have Kussmaul breathing, or their breath may have a characteristic fruity odour. Therefore, we suggest that the patient's breathing pattern should be observed, and if there is a suspicion of DKA, the blood glucose level should be monitored and the urine should be examined.

One could argue that cerebral oedema, caused by the treatment process, cannot be ruled out in our patient. Cerebral oedema, which occurs in $\sim 0.3-1.0 \%$ of DKA episodes in children, is extremely rare in adult patients during the period of treatment of DKA. ${ }^{4}$ However, cerebral oedema is associated with a death rate of $20-40 \%$ in children. ${ }^{5}$ Symptoms and signs of cerebral oedema are variable and include onset of headache, gradual deterioration in level of consciousness, seizures, sphincter incontinence, pupillary changes, papilledema, bradycardia, elevation in blood pressure and respiratory arrest. ${ }^{6}$ The 2009 ADA guidelines on hyperglycaemic crises in diabetes in adults suggested that the prevention of cerebral oedema may be achieved by avoiding excessive hydration and rapid reduction in plasma osmolarity, accomplishing a gradual decrease in serum glucose, and maintaining serum glucose between 250 and $300 \mathrm{mg} / \mathrm{dl}$ until the patient's serum osmolality is normalised and mental status is improved. ${ }^{4}$ However, the data evaluating the outcome and treatment of cerebral oedema in adults are not available, and hence cannot be considered during the therapeutic process. Therefore, the recommendations for treatment are currently based on clinical judgement in the absence of scientific evidence.

In this case, the patient tested positive for HLA-DR4, -DR13, -DQ1 and -DQ4. HLA-DR4-DQ4 has been reported to be the most frequent haplotype in patients with $\mathrm{FT}_{1 \mathrm{DM}}{ }^{7}$ and there is ongoing research regarding the susceptibility of class II HLA subtypes to FT1DM. ${ }^{8}$ CTLA-4 CT60 polymorphism and HLA $B^{*} 4002$ have also been associated with FT1DM in recent reports. ${ }^{9} 10$

Imagawa and Hanafusa ${ }^{8}$ hypothesised that viral infection could trigger an accelerated immune reaction against infected $\beta$-cells, causing massive $\beta$-cell death and FT1DM. In this case, we did not test for viral infections such as parainfluenza virus, Coxsackie virus, enterovirus or human herpes virus 6 or 7 . However, physicians should consider FT1DM when viral infections are prevalent.
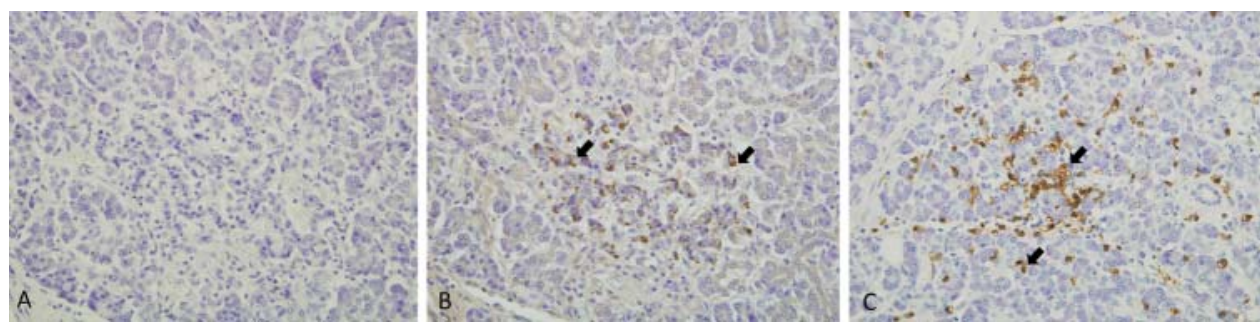

Figure 1 Serial sections of the pancreas stained for antibodies to insulin $(A)$ and glucagon $(B)(\times 400)$. No insulin-positive cells $(A)$, but few glucagon-positive cells $(B$, arrow), are observed. Pancreatic tissue stained for antibodies to CD8 $(C$, arrow $)(\times 400)$. 


\section{Learning points}

- Fulminant type 1 diabetes mellitus (FT1DM) is rare disease, with an extremely rapid progression to critical illness and a poor outcome.

- FT1DM has been reported in both East Asian and Caucasian populations.

- As the most common symptoms of FT1DM are similar to those of common cold, FT1DM may be missed clinically in a region where the common cold is prevalent.

- During the therapeutic process for FT1DM, we should consider the prevention of cerebral oedema by avoiding excessive hydration and rapid reduction of plasma osmolarity, accomplishing a gradual decrease in serum glucose, and maintaining serum glucose between 250 and $300 \mathrm{mg} / \mathrm{dl}$ until the patient's serum osmolality is normalised and mental status is improved.

Competing interests None.

Patient consent Obtained.

\section{REFERENCES}

1. Hanafusa $\mathbf{T}$, Imagawa A. Fulminant type 1 diabetes: a novel clinical entity requiring special attention by all medical practitioners. Nat Clin Pract Endocrinol Metab 2007;3:36-45; quiz 2p following 69.

2. Moreau C, Drui D, Arnault-Ouary G, et al. Fulminant type 1 diabetes in Caucasians: a report of three cases. Diabetes Metab 2008;34: 529-32.

3. Imagawa A, Hanafusa T, Uchigata $Y$, et al. Fulminant type 1 diabetes: a nationwide survey in Japan. Diabetes Care 2003;26:2345-52.

4. Kitabchi AE, Umpierrez GE, Miles JM, et al. Hyperglycemic crises in adult patients with diabetes. Diabetes Care 2009;32:1335-43.

5. Wolfsdorf J, Glaser N, Sperling MA, et al. Diabetic ketoacidosis in infants, children, and adolescents: a consensus statement from the American Diabetes Association. Diabetes Care 2006;29:1150-9.

6. Marcin JP, Glaser N, Barnett P, et al. Factors associated with adverse outcomes in children with diabetic ketoacidosis-related cerebral oedema. J Pediatr 2002;141:793-7.

7. Imagawa A, Hanafusa T, Uchigata $Y$, et al. Different contribution of class II HLA in fulminant and typical autoimmune type 1 diabetes mellitus. Diabetologia 2005;48:294-300.

8. Imagawa A, Hanafusa T. Fulminant type 1 diabetes — an important subtype in East Asia. Diabetes Metab Res Rev 2011;27:959-64.

9. Kawabata $\mathbf{Y}$, Ikegami H, Awata T, et al. Differential association of HLA with three subtypes of type 1 diabetes: fulminant, slowly progressive and acute-onset. Diabetologia 2009;52:2513-21.

10. Kawasaki $\mathbf{E}$, Imagawa $\mathrm{A}$, Makino $\mathrm{H}$, et al. Differences in the contribution of the CTLA4 gene to susceptibility to fulminant and type $1 \mathrm{~A}$ diabetes in Japanese patients. Diabetes Care 2008;31:1608-10.

This pdf has been created automatically from the final edited text and images.

Copyright 2012 BMJ Publishing Group. All rights reserved. For permission to reuse any of this content visit

http://group.bmj.com/group/rights-licensing/permissions.

BMJ Case Report Fellows may re-use this article for personal use and teaching without any further permission.

Please cite this article as follows (you will need to access the article online to obtain the date of publication).

Inokuchi R, Matsumoto A, Odajima H, Shinohara K. Fulminant type 1 diabetes mellitus. BMJ Case Reports 2012;10.1136/bcr-2012-006560, Published XXX

Become a Fellow of BMJ Case Reports today and you can:

- Submit as many cases as you like

- Enjoy fast sympathetic peer review and rapid publication of accepted articles

- Access all the published articles

- Re-use any of the published material for personal use and teaching without further permission

For information on Institutional Fellowships contact consortiasales@bmjgroup.com

Visit casereports.bmj.com for more articles like this and to become a Fellow 